\title{
Development of the Environmental, Social and Economic Sustainability in the Peri-Urban Agricultural Areas: Governance Opportunities in the South Milan Agricultural Park
}

\author{
Anna Gaviglio ${ }^{1, a}$, Alberto Pirani ${ }^{1, b}$ and Mattia Bertocchi ${ }^{1, c}$ \\ ${ }^{1}$ Università degli Studi di Milano, Dipartimento di Scienze veterinarie per la salute, la produzione \\ animale e la sicurezza alimentare (VESPA), Via Celoria 2, Milano (Italy). \\ aanna.gaviglio@unimi.it, balberto.pirani@unimi.it, ’ mattia.bertocchi@unimi.it
}

Keywords: Peri-Urban Areas, Urbanization, Local Institutions, Milan Metropolitan Area, Multifunctional Agriculture.

\begin{abstract}
Farms located in economically advanced areas in close contact with large cities, industrial areas and major infrastructure, may be subjected to the pressure of negative externalities beyond the agricultural sector. This work is based on the study of the interactions between the metropolitan area of Milan and the agricultural activities around it. We decided to assess the 3 scales of sustainability (environmental, social, economic) of farms to create a means to guide the local institution (the Parco Agricolo Sud Milano, PASM) towards innovative and sustainable solutions. The survey was carried out through a tool that compares farms through indicators, integrating agricultural production with environmental protection. It assesses the strengths and weaknesses of the production system and the ways to improve the level of sustainability. We sampled farms and collected their data (from database, interviews, estimates, observations, tabulated data). The results highlight that what had been done so far by the PASM has provided valid economic tools for large multifunctional farms which network is deeply tied to the local contest, through services such as direct sales, the short chain, agritourism and related activities. This has certainly contributed to the improvement of environmental conditions and landscape of the area, which the population of Milan has often shown appreciation. On the other hand, large and small specialized farms, not characterized by these sources of income, have not received equal contribution.
\end{abstract}

\section{Introduction}

\subsection{The agriculture in the peri-urban areas: the Parco Agricolo Sud Milano (PASM)}

Most of the future development in Europe will occur in peri-urban areas along the biggest cities. Checking the growth of urbanization is the primary tool for balanced territorial development through a proper land management. In the process of urbanization, the peri-urban agricultural areas fall under pressure of development and there arise the potentiality to abolish the identity of rural area [1].

From the agricultural point of view, the literature identifies 3 main critical points of these areas: (i) they are often more valuable for development, thus farmers earn more by selling the land to developers as agriculture is still a low-profitability sector [2]; (ii) the fragmentation of farm area, inversely proportional to the distance from the city [3], involves the splitting of farm property into smaller units, reducing the efficiency of the enterprise; (iii) as a consequence of point 2 , the reduction of the farm agricultural area also leads to a reduction of the economic size of farms [2].

The Parco Agricolo Sud Milano (PASM, South Milan Agricultural Park), established in the 1990, is a metropolitan agricultural park that involves the peri-urban area around the city of Milan ${ }^{1}$. It has the objectives of the preservation of the environment and supporting the economy of agricultural production. The area is completely flat, farming is extremely developed, the population density is high and land has the typical attributes of peri-urban areas (fragmentation, competition from industries, high value of the land). The main economic possibilities of food farms in the area seems to

\footnotetext{
${ }^{1}$ The PASM, with 61 municipalities, covers an area of about 47,000 hectares (approximately 37,000 hectares of agricultural surface and 19,000 hectares of urbanized territory) and involves approximately 1000 farms.
} 
be 3: (i) to sell the produce to big processors; (ii) to sell to big retailers; (iii) to sell through short chain tools.

Currently, the PASM operates through two documents [4]: the Norme Tecniche di Attuazione (NTA, Technical Norms) and the Piano di Settore Agricolo (PSA, Agricultural Plan). They contain a large number of rules and regulations aimed to: (i) protect the agricultural activities, (ii) promoting new job opportunities in the agricultural sector, especially young people, (iii) introduce more sustainable farming practices and lower impact agronomic techniques such as organic farming, (iii) enhance the landscape, the environment, the cultural and historical heritage, protect the water resources.

In over 20 years, the Park has paid particular attention to the environmental and natural aspects of the area and to aspects related to the development of short supply chains, direct sales, the ethical purchasing groups, agritourisms and recreational activities. The article 15 of the PSA identifies the 6 modes of action for the innovation of the area:

1) Quality brands: nowadays, it was created only one brand, called "Azienda agricola-produttore di qualità ambientale" (farm-producer of environmental quality) with the objectives of enhancing and protecting agricultural activities, the environmental and landscape protection, the land conservation, the promotion of food products in the metropolitan area, the sustainability of production processes, the enhancement of short chain and the food safety. The brand has so far gathered the support of only 27 farm;

2) Organic farming: currently no relevant initiatives have been started, since today the amount of the organic farms not exceed 20 units;

3) Landscape and environment certifications: currently no relevant initiatives have been started;

4) RDP agri-environmental measures: currently no relevant initiatives have been started;

5) Agri-tourism activities: initiatives aimed at the communication and information to citizen about agrotourisms, education, accommodation and other secondary activities related to agriculture;

6) Rural and natural landscapes: projects have been undertaken in rural areas for favoring the enjoyment by citizens of Milan (the protection of the indigenous flora and fauna, the rural buildings, the resurgences and the water meadows otherwise easily abandoned).

\subsection{Evaluation of the sustainability of the peri-urban agricultural area of Milan}

Considering the concept of sustainability in agriculture, it is necessary to distinguish its different aspects closely linked each other: (i) Environmental; (ii) Social; (iii) Economic.

Our project, based on the study of the interactions between the metropolitan area of Milan and the agricultural activities around it, aims to develop a support for the PASM, useful for the evaluation of its programming policy for farmers, and the attestation of the positive externalities resulting from decisions undertaken in the interests of Park. Our approach is based on the idea that in a territory where the agriculture is strongly influenced by the presence of other productive activities and especially because localized close to a large city such as Milan, these factors can be used positively.

Therefore, it is interesting to evaluate the role of the PASM as institution in the new scenarios of development of this area, and the effects of the decisions of the local policies, already taken or witch might be taken in future, aimed at the production of different environmental and commercial services. We decided to use indicators, included in synthetic applications, useful for fast surveys, applicable to different and unrelated situations, based on data already available or easy to collect [5].

\section{Material and methods}

Our survey was carried out through the creation of a method for the sustainability evaluation based on calculations, measurements and evaluations. We have selected 41 quantitative indicators $[6,7,8]$ (Figure 1), modified, weighed and calibrated as a function of their importance in the sustainability of the area. These indicators characterize the components (9) of sustainability. The results are represented by indexes, with more concise and representative values that aggregate more than one indicator that facilitates the use of complex information by non-experts [9]. 


\begin{tabular}{|c|c|c|}
\hline $\begin{array}{l}\quad \text { 1_Biodiversity } \\
\text { 1_Diversity of temporary crops } \\
\text { 2_Diversity of permanent crops } \\
\text { 3_Animal Diversity } \\
\text { 4_Development and conservation of the } \\
\text { species }\end{array}$ & $\begin{array}{l}\text { 2_Spaces management } \\
\text { 5_Crop Rotation } \\
\text { 6_Size of plots } \\
\text { 7_Management of organic matter } \\
\text { 8_Buffer zones } \\
\text { 9_Environmental Safeguard } \\
\text { 10_Stocking rate } \\
\text { 11_Management of forage areas }\end{array}$ & $\begin{array}{l}\text { 4_Agricultural practices } \\
\text { 12_Fertilization } \\
\text { 13_Management of livestock effluents } \\
\text { 14_Pesticides } \\
\text { 15_Veterinary treatments } \\
\text { 16_Soil protection } \\
\text { 17_Water management } \\
\text { 18_Use of the energy }\end{array}$ \\
\hline $\begin{array}{l}\text { 5_Quality of products and the } \\
\text { territory } \\
\text { 19_High quality brands } \\
\text { 20_Development of rural landscape } \\
\text { 21_Management of non-organic wastes } \\
\text { 22_Access to spaces } \\
\text { 23_Social implications }\end{array}$ & $\begin{array}{l}\text { 6_Services and short chains tools } \\
24 \text { _Development of short chain } \\
\text { 25_Autonomy and exploitation of local } \\
\text { resources } \\
26 \text { 2_Multifunctionality } \\
27 \text { Contribution to employment } \\
28 \text { _Cooperative work } \\
\text { 29_Future prospects }\end{array}$ & $\begin{array}{l}\text { 7_Work, ethics, human development } \\
\text { 30_Contribution to the balance and sustainable } \\
\text { management of resources } \\
\text { 31_Animal Welfare } \\
\text { 32_Education } \\
\text { 33_Work } \\
\text { 34_Quality of life } \\
\text { 35_Isolation } \\
\text { 36_Hygiene and safety }\end{array}$ \\
\hline $\begin{array}{l}\text { 8_Profitability } \\
\text { 37_Viability } \\
\text { 38_Economic specialization }\end{array}$ & $\begin{array}{l}\text { 9_Independence } \\
\text { 39_Financial autonomy } \\
\text { 40_Dependency from PAC aid }\end{array}$ & $\begin{array}{l}\text { 10_Efficiency } \\
41 \_ \text {Efficiency of the production process }\end{array}$ \\
\hline
\end{tabular}

Figure 1: 41 indicators, 9 component of sustainability.

The research involved: (i) the observation of the farms, by using of a database named SIARL ${ }^{2}$ containing their quantitative characteristics (size, production, livestock, etc.); (ii) sampling of the detectable farms and selection of 30 farms by a stratification considering the type and the method of production $^{3}$, the economic dimension ${ }^{4}$ and the geographical localization ${ }^{5}$ and the activities; (iii) creation of a database collecting the necessary data from SIARL, SITPAS ${ }^{6}$, interviews (questionnaire) to farm personnel, observations and tabulated data $\left(\mathrm{RICA}^{7}\right)$; (v) selection of the indicators; (iv) calculation of the indicators.

\section{Results and discussion}

The comparison of the results represented with a spider graph provides a preliminary characterization of sustainability [10]. Aggregating the analyzed farms for major categories (economic and functional), we can establish a connection between this type of categorization and the environmental and social contribution that these farms offer to the society and their level of economic sustainability (crucial for their presence in this difficult territory, from which it derives the conservation of the agricultural soils).

The smaller farms usually achieve good results in the environmental indicators (especially 1, 2, 3, $5,6,12,14,18$ ), due to a rational use (often definable thrifty) of the input. However, the often-poor economic competitiveness $(37,38,41)$ makes them vulnerable to the high urban interest and, especially in the fringe areas of the city, their important function of preservation of agricultural land is lost. The large farms have been able to achieve excellent economic benefits and the proximity of the city does not cause specific failure: in these cases, the high economic value of land, often subject to strong interest builders, has not yet reached a level that will affect the farm's future $(29,34)$ (Graphic 1).

Multisectoral (more main products and secondary activities) and organic farms get a high score in the environmental indicators (highly linked to the type of production), due to a higher level of plant and animal biodiversity, a virtuous space management and the rational use of the resources.

\footnotetext{
2 "Sistema Informativo Agricoltura Regione Lombardia", from: www.siarl.regione.lombardia.it/index.htm

${ }^{3}$ We considered the main production, the secondary activities and the production methods (organic and conventional).

${ }^{4}$ U.D.E., "Unità di Dimensione Economica" (Unit of Economy Size): high $(>100)$, medium (50 to 100) and low $(<50)$.

${ }^{5}$ We splitted the territory into 4 sectors: 1 (North-West), 2 (South-West), 3 (South-East), 4 (North-East).

6 "Sistema Informativo Territoriale Parco Agricolo Sud Milano", from: www.provincia.mi.it/parcosud/sitpas/index.html

7 "Rete di Informazione Contabile Agricola", from: www.rica.inea.it/public/it/index.php
} 
Multisectoral farms generally get a high score in terms of landscape quality and working conditions. In the economic indicators, diversification and the large conventional systems (especially rice, milk and meat production) are positively valued. Small farms with traditional production systems that do not operate any innovative multifunctional choices highlight more economic difficulties and in these cases the replacement of generation is more difficult. On the contrary, the large farms that represent the most virtuous activities, both multisectoral (economically and socially, with well-established and well-known by citizenship agritourism and direct sales activities) and conventional (land preservation).

In addition, the indicators of multisectoral activities $(24,25,26)$ have shown that large farms have been able to better exploit the instruments put in place by the PASM: the income from these activities has a significant weight on the total, higher than the same indicators for small farms (Graphic 2).

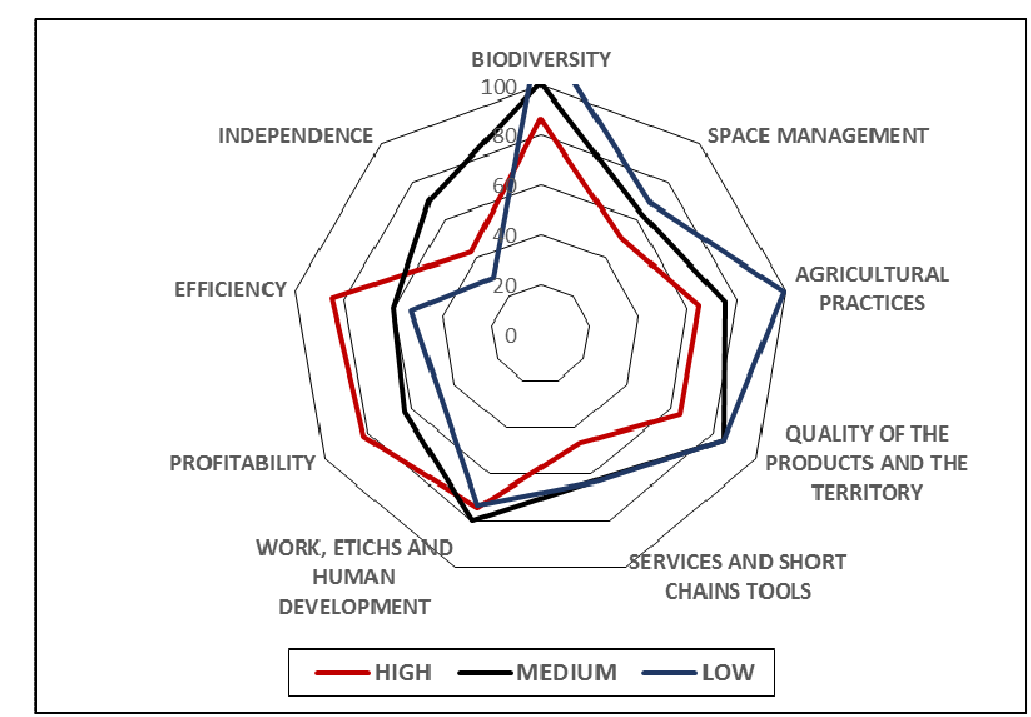

Graphic 1: Aggregation of large (UDE $>100)$ and medium-small $(U D E<100)$ specialized (a major product) and multisectoral farms (more main products and/or secondary activities).

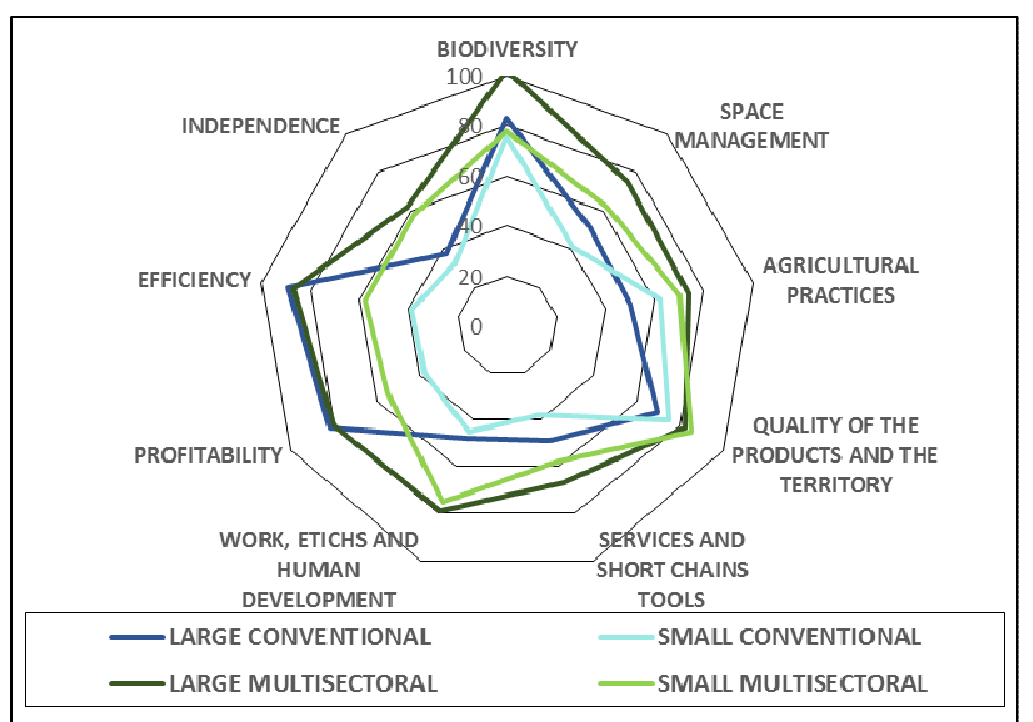

Graphic 2: Aggregation of the farms with a high (>100), medium (50 to 100) and low (<50) value of UDE. 


\section{Conclusions}

The most important activities promoted by the PASM (the development of short chain, the protection of the territory and the promotion of local resources [11]), were often used by the Park as a policy instrument aimed to a higher popular consensus of the citizenship of Milan to the local institution (Provincia di Milano) rather than a real economic tool face to the improvement of the economy of farms. Therefore, we feel the need to be able to integrate the important effort for the development of rural areas, which brings advantages from the environmental (the improvement of the nature of the area) and social (for the important functions offered to the citizenship) point of view, an equally important task of economic and entrepreneurial support for the farms, especially not multifunctional, obviously little interested in the improvement of the landscape and environmental heritage.

These observations are now corroborated by the results of our analysis that, in addition, highlight the need to be able to take advantage of the opportunity of the interest of the citizens of Milan for the nearby rural areas and the need to protect the agricultural production of large and small farms.

Until now, the PASM has provided tools that have been exploited by farms who were already very innovative and they have been able to find a further impetus to their economic development.

Currently, farms that have decided to get the Park's quality brand have other secondary activities besides agriculture. These farms have considered this tool as a marketing opportunity in order to expand their network of direct or a short chain sales and services to the nearest citizenship of Milan.

On contrary, non-diversified small farms without related activities have not been able to reap these opportunities.

In these years, the territory and the economic situation have undergone changes and, in our opinion, the institution needs to move quickly. The attention of the institutions must now be paid to the not diversified small farms located around the city and the large specialized farms, typical of the Po Valley.

In the first case it is necessary to improve their economic sustainability (they need of leaving the old patterns of production to cope the competition of larger farms, economically and technologically competitive) exploiting their social and environmental importance:

1) expanding the opportunities of profit diversifying the production, the marketing, the buyers and the secondary activities (agritourism, school farm, restaurant, etc.) that in a peri-urban context contribute to create a network of consensus that function to preserve agriculture in the area;

2) promoting the creation of new mechanisms of short chains, civic food networks and on-line sales, improving marketing activities, long-term relationships with customers;

3 ) promoting the organic production (which is now only $2 \%$ );

4) the creation of cooperation systems among farms;

5) creating a network of information aimed at obtaining of RDP funds, especially for young entrepreneurs and the agri-environmental measures that for this type of farms require a limited entrepreneurial effort, because often already suited to sustainable production and land management.

Large specialized farms have not shown great interest for the activities promoted by the PASM. In fact, they have not yet been spurred by economic instruments to contribute to the improvement of the social and environmental conditions of the area. In this regard, it is not apparent the need to engage these farms in projects that would be economically unattractive for them, such as short chain, direct sales and quality brands. These farms, however, need of protection because they are elements of great economic importance in the local context and considering the increasing fragmentation and edification of the territory. In this case, it seems useful:

1) creating tools of economic support, i.e. as already experienced by the Ecopoints [12], through the introduction of direct funding for activities related to sustainable production, mechanisms of commercialization, marketing and social activities for the Milan urban area;

2) create free specialized information tools for the knowledge of modern cultivation techniques, farm management, the use of sustainable energy sources, the found opportunities; 
3) working with the LD on common promotional campaigns dedicated to food with PASM logos and creative expressions designed to capture the interest in regional and typical food products.

The role of the research appears relevant and we consider of particularly importance:

1) seeking to grasp the aspects related to consumers of the Milan's urban area, through marketing analysis in order to create a match with those obtained from the supply side;

2) helping to overcome the concept of "bond" (limitations imposed for the safeguard of the environment and the landscape), that must not be considered as disadvantages, but as starting points for innovations. This opportunity is even more interesting for the city of Milan that, hosting the world Expo-2015 with a global theme "Feeding the planet, energy for Life", will have a plus opportunity to reconnect the urban reality to its countryside, to promote the existing farms creating a natural bridge between rural and urban areas;

3) our method allows the integration of new indicators and new components. In our case, referring to a territorial context governed a local institution we perceive the lack of elements of improvement between the farms standing in the area and the institutions whose decisions affect, positively or negatively, their economic, social and environmental role. Nowadays, the consideration of a fourth scale sustainability, called Governance [13] is only a theatrical concept and, to our knowledge, in literature there are not evaluation methodologies. This institutional scale could aim at the evaluation of political choices and the degree of evolution of the relationship between farms and the decision-makers (i.e. information on technologies and regulations, streamlined bureaucracy) and to catalyzing new technological and management choices.

\section{References}

[1] M. S. Uddin, K. Ahmed: Socio-agricultural bridging park: a conceptual urban project in suburban area. In: Journal of Bangladesh Institute of Planners 5, (2012), pp. 129-138

[2] C. Mazzocchi, G. Sali, S. Corsi: Land use conversion in metropolitan areas and the permanence of agriculture: Sensitivity Index of Agricultural Land (SIAL), a tool for territorial analysis. In: Land Use Policy 35, (2013), pp. 155-162

[3] C. Carrion-Flores, E. Irwin: Determinants of residential land-use conversion and sprawl at the rural urban fringe. In: American Journal of Agricultural Economics, 86(4), (2004), pp. 889-904

[4] Information on http://www.provincia.mi.it/parcosud/index.jsp

[5] L. Bechini, N. Castoldi: On-farm monitoring of economic and environmental performances of cropping systems: Results of a 2-year study at the field scale in northern Italy. In: Ecological Indicators, 9(6), (2009), p. 1096-1113

[6] L. Vilain: La méthode IDEA, Edicagri éditions, France (2008)

[7] J-J. Cadilhon, P. Bossard, P. Viaux, P. Girardin, C. Mouchet, L. Vilain: Caractérisation et suivi de la durabilité des exploitations agricoles françaises: les indicateurs de la méthode IDERICA. In: Notes et Etudes Economique,. 26, (2006), pp. 127-158

[8] C. Bockstaller, L. Guichard, O. Keichinger, P. Girardin, M. Galan, G. Gaillard: Comparison of methods to assess the sustainability of agricultural systems. A review. In: Agronomy for Sustainable Development, 29, (2009), pp. 223-235

[9] N. Castoldi, L. Bechini: Integrated sustainability assessment of cropping systems with agro-ecological and economic indicators in northern Italy. In: European Journal of Agronomy, 32(1), (2010), pp. 59-72

[10]P. Girardin, C. Bockstaller, H. M. G. Van der Werf: Assessment of potential impacts of agricultural practices on the environment: the AGRO*ECO method. In: Environmental Impact Assessment, Review 20(2), (2000), pp. 227-239 
[11] Information on http://www.fondazionecariplo.it/it/news/ambiente

[12] P. Mayrhofer: The ecopoint system of Lower Austria: an example of subsidising low intensive farming and evaluation of the ecological, energy and economic performance of farmers. Low Input Farming Systems: an Opportunity to Develop Sustainable Agriculture. In: Proceedings of the JRC, Summer University Ranco, (2007), pp. 92-99

[13] Information on: http://www.fao.org/nr/sustainability/en/ 